\title{
MATHEMATICA Policy Research
}

\section{The Economic Well-Being of Lesbian, Gay, and Bisexual Youth Transitioning Out of Foster Care}

By Amy Dworsky, Chapin Hall, University of Chicago

\section{$M$ any young people aging out of foster care} struggle to achieve economic self-sufficiency during their transition to adulthood. ${ }^{1}$ However, these young people are also a heterogeneous population, and becoming economically self-sufficient can be more of challenge for some compared with others. ${ }^{2}$ Although prior research has looked at racial and ethnic differences in the self-sufficiency of young people who have aged out, differences related to sexual orientation have not been examined. ${ }^{3,4}$

\section{The lack of research on the relationship between} self-sufficiency and sexual orientation represents a major gap in the literature. It is also indicative of a much larger data gap. State child welfare agencies do not routinely track the sexual orientation of youth in foster care, and the kind of population-based studies needed to estimate the percentage of youth in foster care who identify as lesbian, gay, or bisexual (LGB) have not been conducted. This brief describes the characteristics and economic well-being of young people aging out of foster care who identify themselves as LGB. It also compares their characteristics and economic self-sufficiency to that of their heterosexual peers also aging out of care. ${ }^{5}$

The most commonly cited figure for the proportion of foster youth identifying as LGB comes from a 2001 report published by the Lambda Legal Defense and Education Fund,

\section{About This Series}

The Youth Demonstration Development issue brief series provides information for organizations that serve at-risk youth transitioning to adulthood. Funded by the Office of Planning, Research and Evaluation in the Administration for Children and Families, the three-brief series is part of a larger ACF project that developed a framework for promoting the well-being and self-sufficiency of at-risk youth. This brief describes the economic well-being of youth who self-identify as lesbian, gay, or bisexual and those who self-identify as heterosexual. Another brief summarizes the conceptual framework. The third explores occupations in health care and construction that hold promise for at-risk youth in search of employment that does not require extensive education or training. For more information about the Youth Demonstration Development project, please see http://www.acf.hhs.gov/ programs/opre/index.html.

which estimated that between 5 and 10 percent of youth in foster care identify as LGB. ${ }^{6}$ However, that estimate does not appear to have been based on any empirical data collected from or about youth in foster care. Although some who cite this figure also suggest that the actual percentage may be higher because of youth who do not disclose or who actively hide their sexual orientation, they do not present empirical data to support their claims. ${ }^{7,8}$

Perhaps the most accurate statement that can be made at this point is that the percentage of youth in foster care who identify as LGB is not known. What is known, however, is that, like other youth in foster care, many of these young people will not be reunified with their families or placed in adoptive homes. ${ }^{9}$ Instead, they will remain in foster care until they age out when they are 18 or, in some states, 21 years old.

Regardless of how many youth in foster care identify as LGB, there are at least two reasons to predict that it may be especially difficult for them to achieve economic self-sufficiency. First, they are often victims of harassment, discrimination, or even physical violence perpetrated by foster parents, group care staff, or peers. ${ }^{10}$ Some of these young people have been
트OPRE
This brief was funded by the Office of Planning, Research and Evaluation, Administration for Children and Families, U.S. Department of Health and Human Services under Contract Number: HHSP23320095642WC/HHSP23337006T. The ACF project officers were Erica Zielewski and Emily Ball Jabbour. The Mathematica Policy Research project director was M. Robin Dion. OPRE Report \# 2012-41 
rejected or abused by their families because of their sexual orientation. ${ }^{11}$ Victimized yet again because of their sexual orientation, many may run away from their placement to live on the streets where they feel safer. ${ }^{12}$

Second, LGB youth in foster care may be adversely affected by inappropriate or frequent placement changes. Although research has yet to examine differences in placement stability between LGB youth and their heterosexual peers, studies do suggest that placement instability is common for LGB youth. ${ }^{13}$ This instability may preclude the development of permanent connections to supportive adults, ${ }^{14}$ limit the receipt of life-skills training, and interfere with school completion. ${ }^{15,16}$ A shortage of LGB-friendly foster homes also means that many youth who identify as LGB are placed in more restrictive group care settings rather than with families, ${ }^{17}$ which may limit their access to necessary services. ${ }^{18}$

To explore the characteristics and economic well-being of young people aging out of foster care who identify themselves as LGB relative to their heterosexual counterparts, we analyzed data from the Midwest Evaluation of the Adult Functioning of Former Foster Youth (the "Midwest Study"). This longitudinal study followed a sample of young people from Illinois, Iowa, and Wisconsin as they transitioned out of foster care and into adulthood. ${ }^{19}$ Five waves of survey data were collected from these young people from 2002 to 2011: at age 17 or $18(\mathrm{n}=732), 19(\mathrm{n}=603), 21(\mathrm{n}=591)$, 23 or $24(n=602)$, and $26(n=596)$.

\section{Sexual Orientation of Midwest Study Participants}

Midwest Study participants were asked about their sexual orientation at each wave of data collection. ${ }^{20}$ Because of a change in question wording and response options after the baseline interview, ${ }^{21}$ we focus on sexual orientation at waves 2 through 5. At each of those waves, respondents were asked to indicate which of six statements best described themselves: "100 percent heterosexual/ straight," "mostly heterosexual/straight but somewhat attracted to people of the same sex," "bisexual/attracted to men and women equally," "mostly homosexual/gay but somewhat attracted to people of the opposite sex," "100 percent homosexual/gay" or "not sexually attracted to either males or females." We could not examine gender identity because "transgender" was not added as a response option to the question about gender until the final wave of data collection.

To examine change in sexual orientation over time at the aggregate level, we limited our analysis to the 435 young people from whom all five waves of data were collected. Although this approach avoids confounding changes in sexual orientation with sample attrition, our estimates will be biased to the extent that there are systematic differences between the sexual orientation of these young people and their peers for whom at least one wave of data was missing.

Respondents were categorized as heterosexual if they identified themselves as "100 percent heterosexual," as LGB if they identified themselves as something other than 100 percent heterosexual, or as missing data. ${ }^{22} \mathrm{We}$ used this approach because it results in the most inclusive "other" (i.e., non-heterosexual) category. LGB respondents made up 11 to 15 percent of the sample depending on the wave being considered (Table 1). In addition, more change over time was observed among the young women $(n=245)$ than among the young men $(n=190)$.

\section{Characteristics of the LGB and Heterosexual Samples}

Our analysis of economic well-being focused on the 591 study participants who were interviewed at wave 3 when they were 21 years old. ${ }^{23}$ This was the first wave of data collected after all of the study participants had aged out of foster care. Based on the approach described above, 74 percent $(n=437)$ were categorized as heterosexual, 11 percent $(n=67)$ were categorized as LGB, and 15 percent $(\mathrm{n}=87)$ were categorized as missing data.

The LGB respondents looked similar to their heterosexual peers with respect to both their demographic characteristics and placement histories (Table 2), with two exceptions. First, young women made up more than two-thirds of the LGB group compared with only half of the heterosexual group. Second, the LGB respondents experienced more placements, on average, than their heterosexual peers, a difference that was marginally significant at $\mathrm{p}<.10$.

\section{Table 1.}

SELF-REPORTED SEXUAL ORIENTATION BY GENDER $(N=435)$

\begin{tabular}{|c|c|c|c|c|c|c|c|c|c|}
\hline & \multicolumn{3}{|c|}{ LGB $^{a}(\%)$} & \multicolumn{3}{|c|}{ Heterosexual (\%) } & \multicolumn{3}{|c|}{ Missing $^{\mathrm{b}}(\%)$} \\
\hline & Total & Female & Male & Total & Female & Male & Total & Female & Male \\
\hline Wave 2 & 12.0 & 15.9 & 6.8 & 76.8 & 73.1 & 81.6 & 11.2 & 11.0 & 11.6 \\
\hline Wave 4 & 13.1 & 19.2 & 5.3 & 82.1 & 75.9 & 90.0 & 4.8 & 4.9 & 4.7 \\
\hline Wave 5 & 14.7 & 21.6 & 5.8 & 78.2 & 71.0 & 87.4 & 7.1 & 7.3 & 6.8 \\
\hline
\end{tabular}

a Includes respondents who identified as mostly heterosexual but somewhat attracted to people of the same sex, bisexual, mostly homosexual but somewhat attracted to people of the opposite sex, and $100 \%$ homosexual.

b Includes respondents who did not complete the ACASI because they were incarcerated or interviewed by phone, refused to answer or responded "do not know" and reported not being sexually attracted to either males or females. 


\begin{tabular}{|c|c|c|c|}
\hline \multicolumn{4}{|l|}{ DEMOGRAPHICS AND PLACEMENT HISTORIES } \\
\hline & $\begin{array}{c}\text { LGB } \\
(n=67)\end{array}$ & $\begin{array}{l}\text { Heterosexual } \\
\quad(n=437)\end{array}$ & \multirow[b]{2}{*}{$p$-Value } \\
\hline & Percent/Mean & Percent/Mean & \\
\hline Gender & & & * \\
\hline Male & 28.4 & 49.7 & \\
\hline Female & 71.6 & 50.3 & \\
\hline \multicolumn{4}{|l|}{ Race } \\
\hline White & 35.8 & 32.0 & \\
\hline African American & 43.4 & 56.3 & \\
\hline Other & 20.8 & 11.6 & \\
\hline \multicolumn{4}{|l|}{ State } \\
\hline Wisconsin & 22.4 & 31.4 & \\
\hline Illinois & 64.2 & 60.9 & \\
\hline lowa & 13.4 & 7.8 & \\
\hline \multicolumn{4}{|l|}{ Placement History } \\
\hline Ever placed in a foster home & 95.5 & 97.5 & \\
\hline Ever placed with relatives & 49.3 & 46.5 & \\
\hline Ever placed in group care & 59.7 & 56.1 & \\
\hline Ever ran away from foster care & 49.3 & 41.4 & \\
\hline Mean number of placements & 6.8 & 5.4 & + \\
\hline Mean age at most recent foster care entry & 11.7 & 11.3 & \\
\hline Mean age at exit from foster care & 19.4 & 19.5 & \\
\hline
\end{tabular}

*Difference between LGB and heterosexual groups is statistically significant at $\mathrm{p}<.05$.

+ Difference is marginally significant at $\mathrm{p}<.10$.

Prior analyses of the Midwest Study data show that young women aging out of foster care are much more likely than their peers in the general population to become pregnant during their teen years. ${ }^{24}$ Our new analysis shows that female Midwest Study respondents who identified as LGB are nearly as likely to report a pregnancy as the female Midwest Study respondents who identified as 100 percent heterosexual.

Specifically, we found that 60 percent of the young women who were categorized as LGB reported ever being pregnant compared with 69 percent of their heterosexual peers, a difference that is not statistically significant (results not shown in a table). One factor that may help explain the high rate of pregnancy among the young women who were categorized as LGB is that more than half $(n=27)$ of these respondents identified themselves as "mostly heterosexual but somewhat attracted to people of the same sex." Dropping these young women from the analysis reduces the pregnancy rates among the female LGB respondents to 48 percent; however, the between-group difference is still not statistically significant. The "non-significance" may be due to the very small number of females falling within the more restrictive LGB definition $(\mathrm{n}=21)$.

\section{Economic Well-Being of LGB and Heterosexual Samples}

Our analysis of economic well-being covers several domains, including housing, education, employment and earnings, benefit receipt, economic hardships, food security, and assets and debts.

\section{Housing and Homelessness}

We found no statistically significant differences in current living arrangements between the LGB respondents and their heterosexual peers. Approximately 45 percent of both groups were living in their own place. Moreover, although LGB youth are sometimes rejected by their families because of their sexual orientation, a quarter of both groups were living with a biological parent or other relative.

Studies conducted over the past decade have consistently found that a disproportionate number of homeless youth identify as LGB. ${ }^{25}$ Although none of the LGB respondents was currently homeless, more than one in five (22 percent) reported being homeless for at least one night since aging out (results not shown in a table). This rate is not significantly higher than the rate observed among their heterosexual peers (17 percent).

\section{Education}

Although educational attainment is not a direct measure of economic well-being, the two are highly correlated. ${ }^{26} \mathrm{We}$ found no statistically significant differences in educational attainment between the LGB respondents and their heterosexual peers (results not shown in a table) with respect to the percentage who had a high school diploma or GED ( 85 percent versus 76 percent), the percentage who had completed at least one year of college (31 percent versus 30 percent), or the percentage who were still enrolled in school (27 percent versus 24 percent).

\section{Employment and Earnings}

Sixty percent of the LGB respondents were employed at age 21 (Table 3). On average, those who had a job were working 35 hours per week for $\$ 7.82$ per hour. One-quarter of them had no earnings during the past year, and the mean and median earnings of those who had worked were only $\$ 8,621$ and $\$ 6,500$, respectively. Although their heterosexual peers were not more likely to be employed, those who were employed were earning, on average, over a dollar per hour more $(\$ 9.04)$

\section{Benefit Receipt}

The LGB respondents were about as likely as their heterosexual peers to have received cash or in-kind benefits from a number of government programs during the past year (Table 4). However, 
Table 3.

EMPLOYMENT AND EARNINGS

\begin{tabular}{|c|c|c|c|c|c|}
\hline & \multicolumn{2}{|r|}{ LGB } & \multicolumn{2}{|c|}{ Heterosexual } & \multirow[b]{2}{*}{$p$-Value } \\
\hline & $\mathbf{n}$ & Percent/Mean & $\mathbf{n}$ & Percent/Mean & \\
\hline $\begin{array}{l}\text { Percent currently } \\
\text { employed }\end{array}$ & 67 & 59.7 & 437 & 51.7 & \\
\hline $\begin{array}{l}\text { Percent with any earnings } \\
\text { during the past year }\end{array}$ & 66 & 74.2 & 407 & 80.8 & \\
\hline $\begin{array}{l}\text { Mean hours worked } \\
\text { per week (if currently } \\
\text { employed) }\end{array}$ & 41 & 35.3 & 226 & 34.8 & \\
\hline $\begin{array}{l}\text { Mean hourly wage } \\
\text { (if currently employed) }\end{array}$ & 36 & $\$ 7.82$ & 197 & $\$ 9.04$ & * \\
\hline $\begin{array}{l}\text { Mean earnings during the } \\
\text { past year (if any earnings) }\end{array}$ & 50 & $\$ 8,934$ & 326 & $\$ 9,294$ & \\
\hline $\begin{array}{l}\text { Median earnings during } \\
\text { the past year } \\
\text { (if any earnings) }^{a}\end{array}$ & 50 & $\$ 6,500$ & 326 & $\$ 6,000$ & \\
\hline
\end{tabular}

Note: 27 respondents from the full sample of 602 are not included as they had had been incarcerated for at least three months.

${ }^{a}$ Excludes the earnings of four respondents who reported earnings less than $\$ 100$.

${ }^{*}$ Difference between LGB and heterosexual groups is statistically significant at $\mathrm{p}<.05$.

${ }^{+}$Difference is marginally significant at $\mathrm{p}<.10$.

Table 4.

RECEIPT OF GOVERNMENT BENEFITS DURING PAST YEAR

\begin{tabular}{|c|c|c|c|c|c|}
\hline & & GB & Hete & osexual & \\
\hline & $\mathbf{n}$ & Percent & $\mathbf{n}$ & Percent & $p$-Value \\
\hline Earned Income Tax Credit (EITC) & 64 & 24.6 & 411 & 24.6 & \\
\hline Unemployment Insurance & 64 & 6.3 & 410 & 8.5 & \\
\hline Workers' compensation & 64 & 1.6 & 410 & 1.2 & \\
\hline Supplemental Security Income (SSI) & 63 & 17.5 & 410 & 10.2 & * \\
\hline Food stamps (SNAP) & 64 & 62.5 & 410 & 43.5 & * \\
\hline Public housing/rental assistance & 64 & 15.6 & 410 & 9.3 & \\
\hline $\begin{array}{l}\text { Temporary Assistance for Needy } \\
\text { Families (TANF) }\end{array}$ & 27 & 14.8 & 134 & 15.7 & \\
\hline $\begin{array}{l}\text { Special Supplemental Nutrition } \\
\text { Program for Women, Infants, and } \\
\text { Children (WIC) }\end{array}$ & 25 & 68.0 & 108 & 83.3 & \\
\hline
\end{tabular}

${ }^{a}$ Only custodial parents were asked about TANF receipt.

${ }^{\mathrm{b}}$ Only custodial mothers were asked about WIC receipt.

${ }^{*}$ Difference between LGB and heterosexual groups is statistically significant at $\mathrm{p}<.05$.

${ }^{+}$Difference is marginally significant at $\mathrm{p}<.10$.

they were more likely to have received both Supplemental Security Income (SSI) and food stamps (now known as the Supplemental Nutrition Assistance Program, or SNAP).

\section{Economic Hardships}

Sixty-one percent of the LGB respondents experienced at least one of five economic hardships (i.e., not enough money to pay rent, not enough money to pay utility bill, gas or electricity turned off, phone service disconnected, eviction) compared with only 47 percent of their heterosexual peers, a statistically significant difference (Table 5). In particular, the LGB respondents were significantly more likely to report that they did not have enough money to pay rent.
Assets and Debts

We found no statistically significant differences between the LGB respondents and their heterosexual peers with respect to assets (i.e., owning a home or a vehicle) or debts. Just over half of both groups had a bank account, and half were in debt.

\section{Food Security}

Ten items from the USDA's adult food security survey module as well as four additional items (italicized in Table 6) were used to measure food security (Table 6). ${ }^{27}$ Six of the 10 items (bold in the table) were used to construct a food security measure. ${ }^{28}$ The LGB respondents were significantly more likely to give an affirmative answer to 10 of the 14 items and more likely to meet the criteria for being food insecure (i.e., low or very low food security) than their heterosexual peers.

\section{Discussion and Implications}

The data presented in Table 1 suggest that the vast majority of young people aging out of foster care identify themselves as 100 percent heterosexual. However, young women may be more likely than young men to identify as something other than 100 percent heterosexual. This pattern is consistent with longitudinal studies based on nationally representative samples of young people in the general population. That research has found that although self-reported sexual orientation is generally stable during the transition into adulthood, shifts can and do occur, and young men's self-reported sexual orientation seems to be more stable than young women's. ${ }^{29}$

\section{This analysis suggests that LGB} youth aging out of foster care may be at significant risk of not achieving self-sufficiency as they transition to adulthood. At age 21, 60 percent of the Midwest Study participants categorized as LGB were employed, the average wage of those who were working was less than $\$ 8.00$ per hour, and nearly one-quarter had zero earnings during the past year. These findings may explain why so many of the young people were 
Table 5.

ECONOMIC HARDSHIPS DURING THE PAST YEAR (PERCENTAGE)

\begin{tabular}{|l|c|r|}
\hline \multicolumn{1}{|c|}{ LGB (n = 64) } & \multicolumn{1}{c|}{ Heterosexual (n = 410) } \\
\hline Not enough money to pay rent & 37.5 & 25.4 \\
\hline Not enough money to pay utility bill & 35.9 & 26.1 \\
\hline Gas or electricity shut off & 9.4 & 7.5 \\
\hline Phone service disconnected & 42.2 & 31.2 \\
\hline Evicted & 10.9 & 8.3 \\
\hline At least one of the above & 60.9 & 47.2 \\
\hline
\end{tabular}

*Difference between LGB and heterosexual groups is statistically significant at $\mathrm{p}<.05$.

${ }^{+}$Difference is marginally significant at $\mathrm{p}<.10$.

Table 6.

FOOD SECURITY DURING THE PAST YEAR (PERCENTAGE)

\begin{tabular}{|c|c|c|c|}
\hline & LGB (n = 64) & Heterosexual $(n=411)$ & $p$-Value \\
\hline Sometimes/often not enough food to eat & 26.6 & 10.0 & * \\
\hline Didn't eat for a whole day due to no money for food & 20.3 & 9.7 & * \\
\hline Sometimes/often could not afford balanced meals & 46.9 & 21.9 & * \\
\hline Cut size of meals due to lack of money for food & 35.9 & 15.6 & * \\
\hline Didn't eat enough due to lack of money for food & 34.4 & 17.5 & * \\
\hline Hungry but couldn't afford food to eat & 34.4 & 13.6 & * \\
\hline Sometimes/often worried about food running out & 54.7 & 30.7 & * \\
\hline Sometimes/often food ran out/couldn't afford more & 51.6 & 28.7 & * \\
\hline Borrowed money for food from friends or family & 34.4 & 22.1 & \\
\hline \multicolumn{4}{|l|}{ Overall food security (based on 6 items in bold) } \\
\hline High (0 affirmative responses) & 42.2 & 64.5 & * \\
\hline Marginal (1 affirmative response) & 7.8 & 7.1 & \\
\hline Low (2 to 4 affirmative responses) & 21.9 & 19.2 & \\
\hline Very low (5 or 6 affirmative responses) & 28.2 & 9.2 & \\
\hline
\end{tabular}

a Note: 27 respondents from the full sample of 602 are not included as they had had been incarcerated for at least three months.

${ }^{*}$ Difference between LGB and heterosexual groups is statistically significant at $\mathrm{p}<.05$.

${ }^{+}$Difference is marginally significant at $\mathrm{p}<.10$.

receiving food stamps and assistance from other means-tested government programs. Their lack of economic wellbeing was also reflected in the levels of economic hardship, food insecurity, and homelessness we observed.

That said, most of these young people had a high school diploma or GED, nearly one-third had completed at least one year of college, and about one-quarter were still enrolled in school. This may bode well for their future economic well-being.
Our analysis also suggests that study participants who were categorized as LGB were not, for the most part, substantially worse off economically than their heterosexual peers. In addition to having a lower average hourly wage, these young people were more likely to be food insecure, to have received food stamps and SSI, and to have experienced at least one economic hardship. However, we found far more similarities than differences in the measures of economic well-being we examined.
These results suggest that young people aging out of foster care, regardless of their sexual orientation, would stand to benefit from interventions aimed at promoting self-sufficiency.

Young people aging out of foster care who identify as LGB may face additional barriers related to their sexual orientation, and they may have unique needs that service providers and other child welfare professionals should be adequately trained to address. Our 
analysis was limited to outcomes related to economic well-being and did not consider other aspects of well-being such as physical or mental health. Future studies should look at a broader range of outcomes. Additional research with larger and more geographically diverse samples is needed to both the test the generalizability of our results and so that differences between gay, lesbian, and bisexual youth can be examined. Data on gender identity should also be collected so that the experiences of transgender youth can be better understood.

\section{Endnotes}

${ }^{1}$ Courtney, M., A. Dworsky, A. Brown, C. Cary, K. Love, and V. Vorhies. "Midwest Evaluation of the Adult Functioning of Former Foster Youth: Outcomes at Age 26." Chicago: Chapin Hall at the University of Chicago, 2011.

Dworsky, A. "The Economic Self Sufficiency of Wisconsin's Former Foster Youth." Children and Youth Services Review, vol. 27, 2005, pp. 1085-1118.

Goerge, R., L. Bilaver, B. Lee, B. Needell, Brookhard, and W. Jackman. "Employment Outcomes for Youth Aging Out of Foster Care: Final Report." Chicago, IL: University of Chicago Chaplin Center for Children, 2002.

Macomber, J., S. Cuccaro Alamin, D. Duncan, M. McDaniel, T. Vericker, M. Pergamit, Needell, H. Kum, J. Stewart, C. Lee, and R. Barth. "Coming of Age: Empirical Outcomes for Youth Who Age Out of Foster Care in Their Middle Twenties." Washington, DC: U.S. Department of Health and Human Services, 2008.

2 Keller, T., G. Cusick, and M. Courtney. "Approaching the Transition to Adulthood: Distinctive Profiles of Adolescents Aging Out of the Child Welfare System." Social Service Review, vol. 81, 2007, pp. 455-484.

Vaughn, M., J. Shook, and J. McMillen. "Aging Out of Foster Care and Legal Involvement: Toward a Typology of Risk." Social Service Review, 2008, vol. 82, 2008, pp. 419-446.

${ }^{3}$ Dworsky, A., C. Roller White, K. O'Brien, P. Pecora, M. Courtney, R. Kessler, N. Sampson, and I. Hwang."Racial and Ethnic Differences in the Outcomes of Former Foster Youth." Children and Youth Services Review, vol. 32, 2010, 902-912.

${ }^{4}$ We draw a clear distinction between sexual orientation (i.e., attraction to people of the same-sex and/or opposite-sex) and gender identity (i.e., internal identification as male or female) and focus only on the former. Consequently, we do not address the experiences of transgender foster youth whose internal identification as male or female conflicts with their anatomical sex at birth. Although much more research on the experiences of these youth is needed, our data did not include measures of gender identity comparable to our measures of sexual orientation. In fact, this gap in our data reflects an even larger problem. Population-based studies used to estimate the percentage of youth who identify as lesbian, gay, or bisexual have generally not collected the data on gender identity that is needed to estimate the percentage of youth who identify as transgender.

5 Vanessa Vorhies, a doctoral student in the School of Social Service Administration at the University of Chicago, assisted with the data analysis.

${ }^{6}$ Sullivan, C., S. Sommer, and J. Moff. "Youth in the Margins: A Report on the Unmet Needs of Lesbian, Gay, Bisexual, and Transgender Adolescents in Foster Care.” New York: Lambda Legal Defense and Education Fund, 2001.

7 Jacobs, J., and M. Freundlich. "Achieving Permanency for LGBTQ Youth.” Child Welfare, vol. 85, 2006, pp. 299-316.

Wilber, S., C. Ryan, and J. Marksamer. "CWLA Best Practice Guidelines: Serving LGBT Youth in Out-of-Home Care." Washington, DC: Child Welfare League of America, 2006.

Woronoff, R., R. Estrada, and S. Sommer. "Out of the Margins: A Report on Regional Listening Forums Highlighting the Experiences of Lesbian, Gay, Bisexual, Transgender and Questioning Youth in Care." New York: Lambda Legal Defense and Education Fund and the Child Welfare League of America, 2006.

${ }^{8}$ By comparison, approximately 6 percent of the 18- to 24-year-old males and 14 percent of the 18- to 24-year-old females who participated in the third wave of the National Longitudinal Study of Adolescent Health (Add Health) identified themselves as something other than 100 percent heterosexual. See Savin-Williams, R., K. Joyner, and G. Rieger. "Prevalence and Stability of Self-Reported Sexual Orientation Identity During Young Adulthood." Archives of Sexual Behavior, vol. 41, 2012, pp. 103110. Gates (2011), however, discusses the challenges associated with using survey data to measure the size of the LGB population. See Gates, G. "How Many People Are Lesbian, Gay, Bisexual, and Transgender?" Los Angeles: The Williams Institute, UCLA School of Law, 2011.
9 Sullivan, T. "Obstacles to Effective Child Welfare Service with Gay and Lesbian Youths." Child Welfare, vol. 73, 1994, pp. 291-304.

${ }^{10}$ Berberet, H. "Putting the Pieces Together for Queer Youth: A Model of Integrated Assessment of Need and Program Planning." Child Welfare, vol. 85, 2006, pp. 361-384.

Feinstein, R., A. Greenblatt, L. Hass, S. Kohn, and J. Rana. "Justice for All? A Report on Lesbian, Gay, Bi-sexual and Transgendered Youth in the New York Juvenile Justice System.” New York: Urban Justice Center, 2001.

Joint Task Force of New York City's Child Welfare Administration and the Council of Family and Child Caring Agencies. "Improving Services for Gay and Lesbian Youth in NYC's Child Welfare System: A Task Force Report.” New York, 1994.

Mallon, G. "Gay and No Place to Go: Assessing the Needs of Gay and Lesbian Adolescents in Out-of-Home Care Settings." Child Welfare, 1992, vol. 71, pp. 547-556.

Mallon, G. We Don't Exactly Get the Welcome Wagon: The Experiences of Gay and Lesbian Adolescents in Child Welfare Systems. New York: Columbia University Press, 1998.

Mallon, G., N. Aledort, and M. Ferrera. "There's No Place Like Home: Achieving Safety, Permanency, and Well-Being for Lesbian and Gay Adolescents in Out-ofHome Care Settings." Child Welfare, vol. 51, 2002, pp. 407-439.

Sullivan et al., 2001.

Wilber et al., 2006.

${ }^{11}$ Berberet, 2006.

Mallon, 1998.

Ryan, C., and R. Diaz. "Family Responses as a Source of Risk and Resiliency for LGBTY." Paper presented at the Child Welfare League of America Preconference Institute, Washington, DC, 2005.

Sullivan, C. "Kids, Courts and Queers: Lesbian and Gay Youth in the Juvenile Justice and Foster Care Systems." Law and Sexuality: A Review of Lesbian and Gay Legal Issues, vol. 6, 1996, pp. 31-62.

Sullivan et al., 2001.

Wilber et al., 2006.

${ }^{12}$ Sullivan et al., 2001.

Feinstein et al., 2001.

Wilber et al., 2006.

${ }^{13}$ Mallon, 1998.

Mallon et al., 2002.

${ }^{14}$ Mallon et al., 2002.

Feinstein et al., 2001.

${ }^{15}$ Woronoff et al., 2006. 
${ }^{16}$ We are not aware of any studies that have examined differences in placement stability between LGB and heterosexual youth in foster care.

${ }^{17}$ Sullivan et al., 2001.

Wilber et al., 2006.

${ }^{18}$ Mallon, 1992.

Mallon, 1998.

${ }^{19}$ See Courtney et al. (2011) for more information about the design of the Midwest Study.

${ }^{20}$ The sexual orientation question was asked during the audio computer-aided self-interviewing (ACASI) portion of the interview. The ACASI could not be administered to study participants who were incarcerated or interviewed by phone, resulting in missing data for these participants.

${ }^{21}$ At baseline, respondents were asked to identify their sexual orientation as either "heterosexual," "gay or lesbian," or "bisexual."

${ }^{22}$ The "missing data" category included those who did not complete the ACASI because they were incarcerated or interviewed by phone, those who refused to answer or responded "do not know," and those who reported not being sexually attracted to either males or females.

${ }^{23}$ This sample includes the 435 respondents represented in Table 1 plus 156 respondents who were interviewed at wave 3 but not at waves 2, 4, and 5 .

${ }^{24}$ Dworsky, A., and M. Courtney. "The Risk of Teenage Pregnancy Among Transitioning Foster Youth: Implications for Extending State Care Beyond Age 18." Children and Youth Services Review, vol. 32, 2010, pp. 1351-1356.
${ }^{25}$ Quintana, N., J. Rosenthal, and J. Krehely. "On the Streets: The Federal Response to Gay and Transgender Homeless Youth." Washington, DC: Center for American Progress, 2010.

${ }^{26}$ Carnevale, A., S. Rose, and B. Cheah. "The College Payoff: Education, Occupations, Lifetime Earnings." Washington, DC: Georgetown University Center on Education and the Workforce, 2011.

${ }^{27}$ Bickel, G., M. Nord, C. Price, W. Hamilton, and J. Cook. "Guide to Measuring Household Food Security." Washington, DC: U.S. Department of Agriculture, Food and Nutrition Service, Office of Nutrition, Analysis and Evaluation, 2000.

${ }^{28}$ For more information about the short form of the food measure, see Blumberg, S., K. Bialostosky, W. Hamilton, and R. Briefel. "The Effectiveness of a Short Form of the Household Food Security Scale." American Journal of Public Health, vol. 89, 1999, pp. 1231-1234.

${ }^{29}$ Ott, M., H. Corliss, D. Wypij, M. Rosario, and S. Austin. "Stability and Change in Self-Reported Sexual Orientation Identity in Young People: Application of Mobility Metrics." Archives of Sexual Behavior, vol. 40, 2011, pp. 519-532.

Savin-Williams et al., 2012.

Savin-Williams, R., and G. Ream. "Prevalence and Stability of Sexual Orientation Components During Adolescence and Young Adulthood." Archives of Sexual Behavior, vol. 36, 2007, pp. 385-394.
Suggested citation: Dworsky, Amy (2013). The Economic Well-Being of Lesbian, Gay, and Bisexual Youth Transitioning Out of Foster Care, OPRE Report \#2012-41, Washington, DC: Office of Planning, Research and Evaluation, Administration for Children and Families, U.S. Department of Health and Human Services.

This report is in the public domain. Permission to reproduce is not necessary. This report and other reports sponsored by the Office of Planning, Research and Evaluation are available at http://www.acf.hhs.gov/ programs/opre/index.html.

Disclaimer: The views expressed in this publication do not necessarily reflect the views or policies of the Office of Planning, Research and Evaluation, the Administration for Children and Families, or the U.S. Department of Health and Human Services.

For more information about this brief, please contact Amy Dworsky at adworsky@chapinhall.org. This brief and others in this series are available at www.mathematica-mpr.com. 